\section{Review Article}

Ann Liver Transplant 2021;1(1):71-78

https://doi.org/10.52604/alt.21.0007

Check for updates
ALT

pISSN 2765-5121

eISSN 2765-6098

\title{
Tailored standardization of portal vein reconstruction for pediatric liver transplantation at Asan Medical Center
}

\author{
Shin Hwang, Jung-Man Namgoong
}

Department of Surgery, Asan Medical Center, University of Ulsan College of Medicine, Seoul, Korea

Received March 9, 2021

Revised March 24, 2021

Accepted April 1, 2021

Corresponding author: Shin Hwang Department of Surgery, Asan Medical Center, University of Ulsan College of Medicine, 88 Olympic-ro 43-gil, Songpa-gu, Seoul 05505, Korea

E-mail: shwang@amc.seoul.kr https://orcid.org/0000-0002-9045-2531

(c) The Korean Liver Transplantation Society This is an Open Access article distributed under the terms of the Creative Commons Attribution Non-Commercial License (http://creativecommons.org/licenses/ by-nc/4.0/) which permits unrestricted non-commercial use, distribution, and reproduction in any medium, provided the original work is properly cited.
Pediatric recipients, especially infants, are vulnerable to vascular complications because recipient vessels are smaller than those in adult liver transplantation (LT). Once portal vein (PV) stenosis occurs, it is often difficult to treat it through radiological angioplasty. Endovascular stenting is regarded as the final life-saving procedure, with a likelihood of needing retransplantation later. We have established standardized customization of surgical techniques for pediatric LT. Here, we present our tailored standardization of PV reconstruction for pediatric LT with the following 5 topics. 1) tadpole vein homograft conduit interposition for hypoplastic PV in infant patients undergoing split or living donor LT; 2) side-to-side anastomosis for hypoplastic PV in infant patients undergoing infant-to-infant whole liver LT; 3) PV branch patch venoplasty for size-matching in pediatric patients undergoing split or living donor liver transplantation; 4) PV conduit interposition in pediatric patients with congenital absence of PV; 5 ) wedged patch venoplasty for small-sized graft left PV. There are two features in our techniques for PV reconstruction: 1) frequent use of vein homograft; and 2) funneling of the recipient PV to match with the graft PV. In conclusion, secure PV reconstruction is important for successful pediatric LT. Thus, every effort should be made to ensure obtainment of sufficient portal blood inflow. From the viewpoint of hemodynamics principles, a funnel-shaped PV conduit is the most desirable configuration to ensure effective flow from the splanchnic system in infant patients with PV hypoplasia.

Keywords: Portal vein stenosis; Endovascular stenting; Vascular insufficiency; Portal vein hypoplasia; Vein homograft

\section{INTRODUCTION}

Various innovative surgical techniques have been proposed to improve the outcomes of pediatric liver transplantation (LT) because vascular complications can occur in a not negligible proportion of pediatric LT recipients. Pediatric recipients, especially infants, are vulnerable to vascular complications because recipient vessels are smaller than those in adult LT. Once hepatic vein or portal vein (PV) stenosis occurs, it is often difficult to treat it through radiological angioplasty because connective tissues around the stenosis are firmly attached and resistant to mechanical expansion [1-4]. Insertion of a wall stent to vascular anastomotic stenosis is considered as an effective rescue 
treatment that ensure long-term patency in adult recipients. In contrast, in pediatric recipients, such stent insertion is regarded as the final life-saving procedure, with a likelihood of needing retransplantation later because such a vascular wall stent may not expand sufficiently during the physical growth of the recipient from infant to adolescent [5]. Therefore, vascular reconstruction requires a secure surgical design in pediatric LT recipients, particularly in infant patients.

Individually designed reconstruction techniques customized to each pediatric LT operation have contributed to a decrease in vascular complications. However, they are technically liable due to the lack of validation. Thus, large experience with matured techniques is required to ensure satisfactory outcomes. Since we have achieved better results following standardization than using individualized customization in the reconstruction techniques for adult living donor liver transplantation (LDLT) [6,7], we have also established standardized customization of surgical techniques for pediatric LT in our institution. Here, we present our tailored standardization of PV reconstruction for pediatric LT.

\section{TADPOLE VEIN HOMOGRAFT CONDUIT INTERPOSITION FOR HYPOPLASTIC PORTAL VEIN IN INFANT PATIENTS UNDERGOING SPLIT OR LIVING DONOR LT}

Hypoplasia of the PV often occurs in pediatric patients with biliary atresia. Various surgical techniques have been developed to reconstruct such stenotic PVs, but these techniques resulted in a non-negligible incidence of PV complications [8-11]. For sclerotic PVs with a very small caliber, longitudinal patch venoplasty is often insufficient, even after applying an extended incision into the superior mesenteric vein (SMV)-splenic vein (SV) confluence. Thus, PV interposition with a sizable vein graft is essentially the most effective solution that can provide sufficient portal blood flow to the graft liver. For PV graft interposition, endto-end anastomosis technique at the SMV-SV confluence has been often used. However, in infant patients, simple end-to-end anastomosis using a sizable vein homograft, such as an adult iliac vein homograft, does not provide a sufficiently wide anastomotic area due to the overt size-mismatch between the recipient PV and the iliac vein graft.

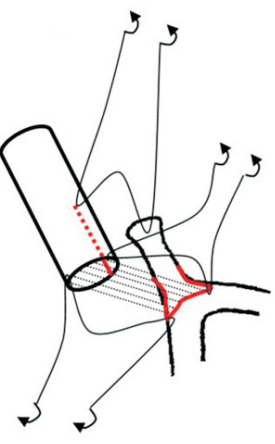

(A)
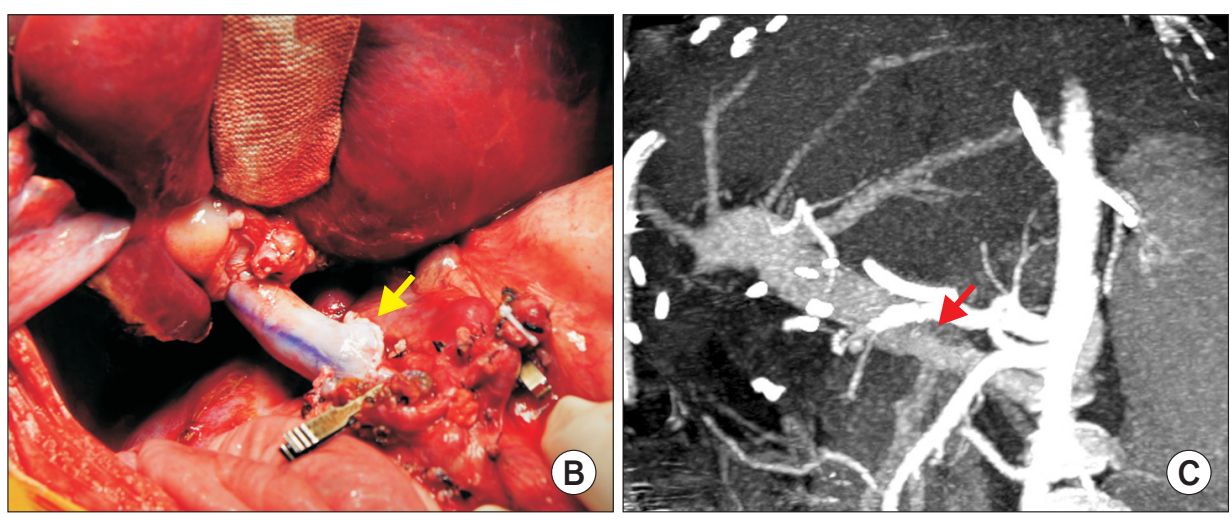

Fig. 1. The technique of tadpole anastomosis for portal vein reconstruction using vein homograft interposition. (A) Illustration of the technique to achieve optimal combination of the recipient portal vein stump and vein homograft end. A longitudinal slit at the vein homograft is automatically widely opened by suture-induced tension and portal vein blood pressure. (B) An operative field photograph is taken after portal reperfusion. An arrow indicates the anastomosis line. The longitudinal axis of the interposed vein homograft is marked to facilitate anastomosis without twisting. (C) Follow-up computed tomography scan taken at 1 week after transplantation shows smooth stenosis-free transition from the recipient-side superior mesenteric vein-splenic vein confluence to the interposed vein homograft (arrow). 
For these patients, we developed a technique of tadpole anastomosis (Fig. 1) [12]. This technique has two features. The first feature is the establishment of a wide patch expansion effect at the SMV-SV confluence. Extensive dissection of the SMV and SV fully exposes the confluence region. However, the vein wall at the confluence in infant patients is very thin, substantially thinner than the wall of an ilio-femoral vein homograft. To prevent unwanted tearing or roll-over, we initially make a longitudinal incision only. After suturing at the bottom of this niche, two small transverse incisions are applied laterally, which incise some of the SMV and SV wall. The actual incision has an inverted-T shape, which may be similar to an inverted-Y incision. We sequentially add bidirectional transverse incisions to enhance the patch effect over that obtained with a simple longitudinal incision.

The second feature is a streamlined PV anastomosis at the SMV-SV confluence. The diameter of a vein homograft is much larger than that of a pediatric recipient SMV; therefore, based on the fluid dynamics principles, a gradual transition of vessel diameter as like funneling is beneficial [12]. Insertion of a wedge with a native PV patch facilitates a smooth transition from the SMV-SV confluence to the PV conduit. This technique also requires a very long suture line, approximately double the circumference of the effec- tive anastomotic area, which minimizes the risk of an anastomotic purse-string effect due to physical growth of the infant patient. This technique is named 'tadpole anastomosis' because the widening patch effect is mostly achieved by the belly portion while the funneling effect is induced by the tail portion.

\section{SIDE-TO-SIDE ANASTOMOSIS FOR HYPOPLASTIC PORTAL VEIN IN INFANT PATIENTS UNDERGOING INFANT-TO-INFANT WHOLE LIVER LT}

Infant recipients with biliary atresia often exhibit overt PV hypoplasia and underdevelopment of the splanchnic blood flow system. Thus, secure PV reconstruction is a major matter of concern [10-12]. Especially for biliary atresia in infants with growth retardation, the PV can be exceptionally small and poorly developed. The abovementioned tadpole anastomosis is a useful technique for PV hypoplasia, but it cannot be applied to infant-to-infant whole liver LT because the PV of an infant liver graft is also very small.

For secure PV reconstruction, the effective size of the anastomotic cross-sectional area and a streamlined configuration without axial rotation are two essentially important parameters [12]. We have developed a side-to-side unifi-
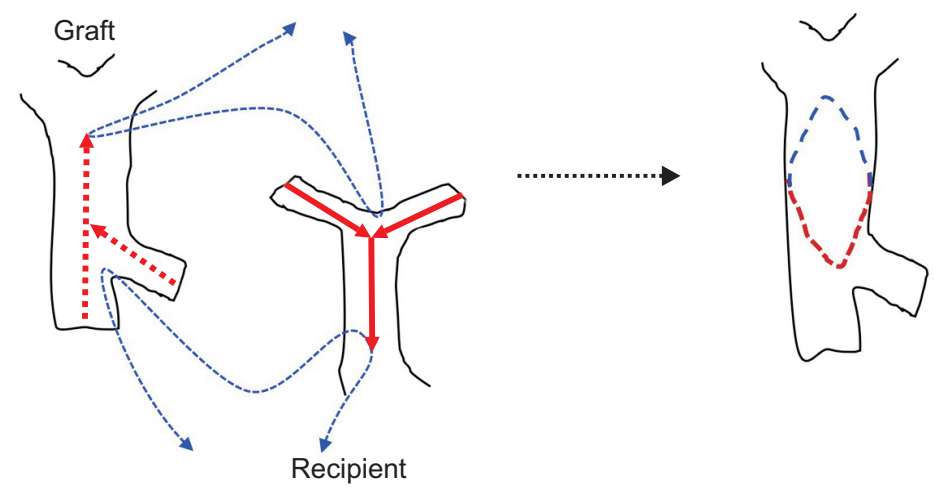

Recipient
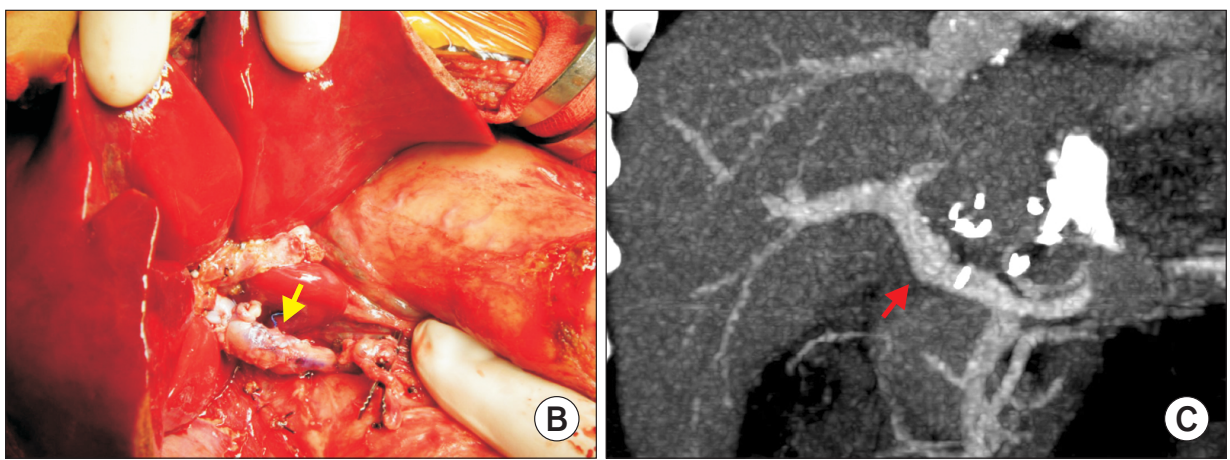

Fig. 2. The technique of side-to-side unification of the portal vein in infant-to-infant whole liver transplantation. (A) Illustration of the technique: a deep longitudinal incision is made at the 6 o'clock direction of the graft portal vein (PV) and the 12 o'clock direction of the recipient PV. Running sutures are then used to unify these two PVs. This technique creates an enlarged conduit from the superior mesenteric vein-splenic vein confluence to the hilar PV confluence. (B) An operative field photograph is taken after portal reperfusion, in which PV anastomosis appears to be enlarged (arrow). (C) Follow-up computed tomography scan taken at 1 year after transplantation shows normal configuration of the PV system. Arrow indicates the site of PV anastomosis. 
cation technique for anastomosis of two small PVs [13]. A deep longitudinal incision is made in the 6 o'clock direction of the graft PV and the 12 o'clock direction of the recipient $\mathrm{PV}$; then, continuous sutures was then used to unify these two PVs, thus generating an enlarged conduit from the SMV-SV confluence to the graft hilar PV confluence (Fig. 2). The unified portion of the PV anastomosis expands markedly, which prevents anastomotic stricture.

\section{PV BRANCH PATCH VENOPLASTY FOR SIZE-MATCHING IN PEDIATRIC PATIENTS UN- DERGOING SPLIT OR LIVING DONOR LIVER TRANSPLANTATION}

The size of a graft PV is usually much larger than that of a recipient of split or living donor LT, even in pediatric patients with normal PV. To compensate the size discrepancy in PV diameter, anastomosis using recipient PV branch patch directly or branch patch venoplasty is frequently used (Fig. 3). It is essential to obtain the recipient's first-order PV branches as long as possible to use them effectively $[14,15]$.

\section{PV CONDUIT INTERPOSITION IN PEDIATRIC PATIENTS WITH CONGENITAL ABSENCE OF PV}

Congenital absence of the PV is a rare venous malformation in which mesenteric venous blood drains directly into the systemic circulation $[16,17]$. In patients with absence of PV stump at the portocaval shunt, a new PV can be made using vein conduit interposition as an end-toside anastomosis to the portocaval shunt (Fig. 4) $[18,19]$. The prerequisite for reconstruction with vein conduit is the availability of adequate vein homograft. A cold-stored fresh iliac or femoral vein homograft appears to be the most suitable for PV interposition because cryopreserved vein carries a risk of aneurysmal dilatation or shrinkage later.

\section{WEDGED PATCH VENOPLASTY FOR SMALL-SIZED GRAFT LEFT PV}

PV size-matching between the recipient and liver graft is important to prevent anastomotic stenosis in split or living donor LT. If the diameter of graft left PV is $<8 \mathrm{~mm}$, it can induce anastomotic stenosis even though a growth factor is fully given at the suture material. Generally, graft PV wid-


(A) venoplasty in pediatric recipients. (A) Two first-order portal vein (PV) branches are transected and their central line is incised to make long PV branch patches. The branch patch can be anastomosed to the graft PV directly or after making a funnel through unification venoplasty. (B) An operative field photograph is taken after portal reperfusion, in which the PV anastomosis site is smoothly expanded (arrow). (C) Follow-up computed tomography scan taken at 4 days after transplantation shows a slight anastomotic stenosis (arrow) of the PV probably due to tension at the anastomosis site. 

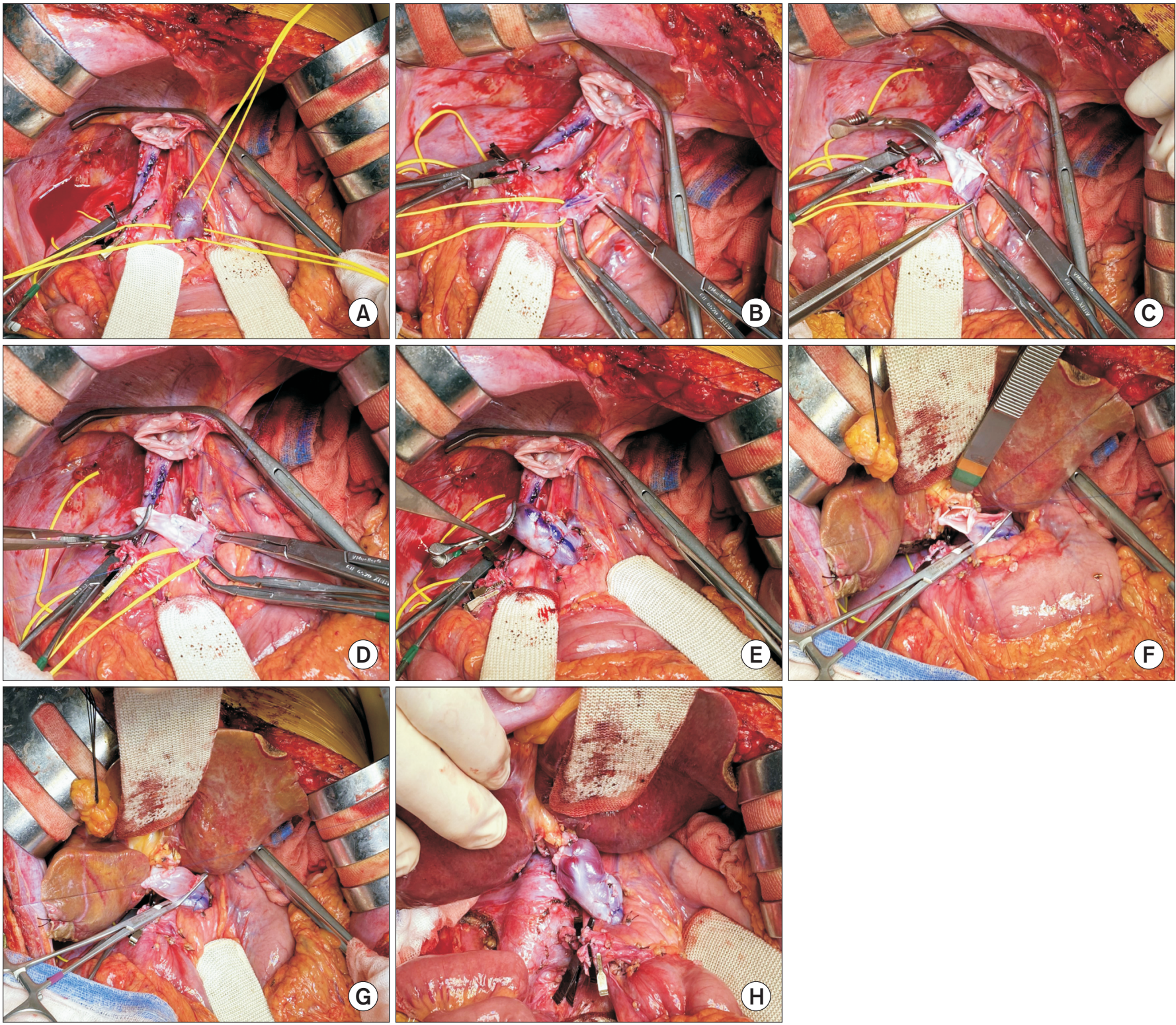

Fig. 4. Intraoperative photographs for portal vein (PV) interposition graft in a pediatric patient with congenital absence of the PV. (A) The confluence portion of the superior mesenteric vein-splenic vein is meticulously dissected. (B) The vein branches at the confluence portion are securely clamped and a longitudinal incision is made at the confluence portion. (C-E) A cold-stored fresh iliac vein conduit is anastomosed to the confluence portion in an endto-side fashion. $(F, G)$ The PV conduit is anastomosed with the graft PV. $(H)$ The PV conduit is expanded after portal reperfusion.

ening is not considered because graft PV is considered as a no-touch area. However, an exceptionally small left PV can be indicated for wedged patch venoplasty. To release the waist at the graft PV stump, a longitudinal incision is made at the graft PV stump and a small iliac vein homograft patch is attached to widen the graft PV orifice (Fig. 5) [20]. The size of the patch can be adjusted to match with the size of the recipient PV.

\section{DISCUSSION}

Patient survival outcome after individualized customization of vascular reconstruction is excellent in both adult and pediatric LDLT. However, we observed that a small proportion of patients are still at risk of vascular complications due to unusual liver anatomy and/or inappropriate reconstruction customization $[21,22]$. To minimize the risk 

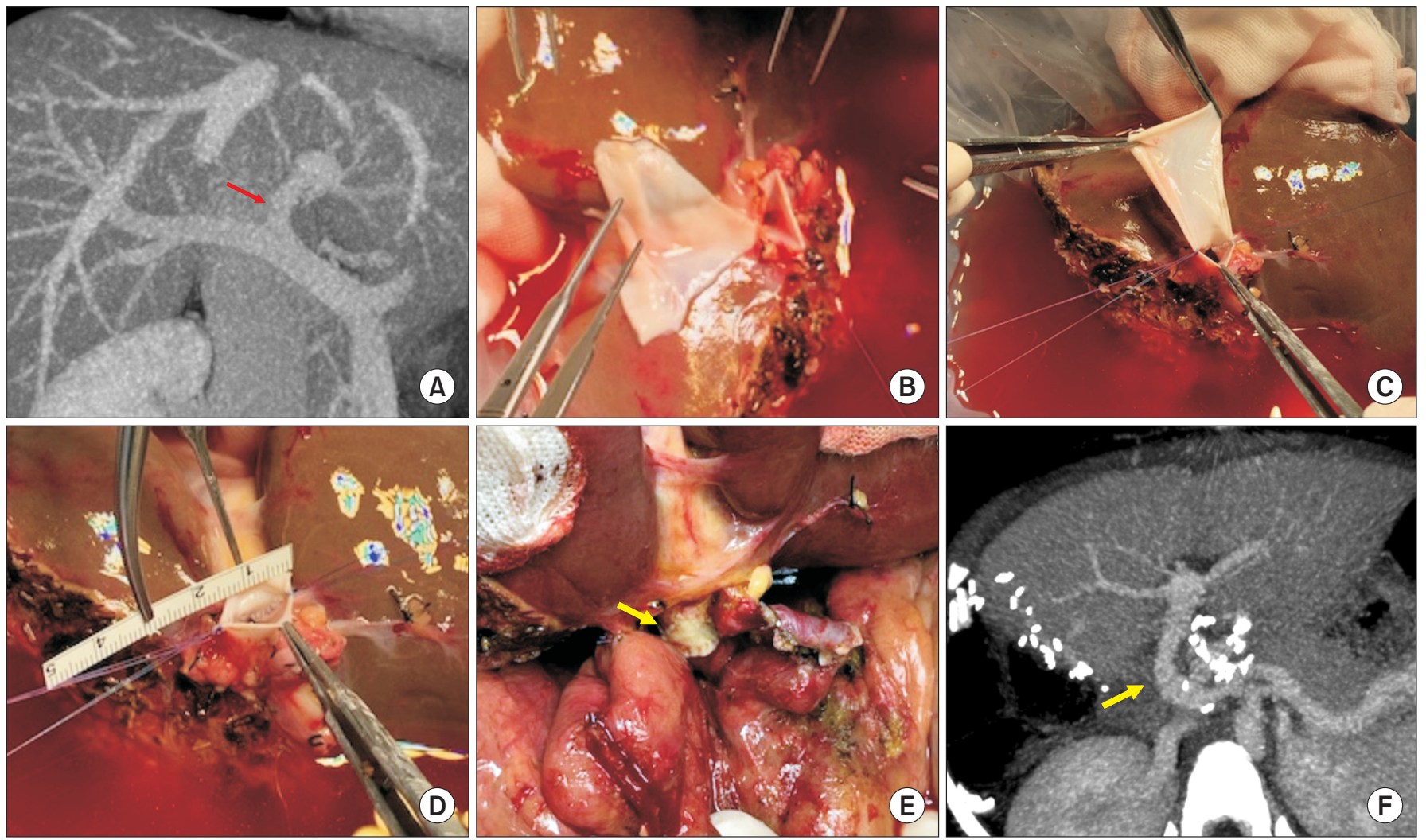

Fig. 5. Wedged-patch venoplasty of the waisted left portal vein of a left liver graft. (A) Computed tomography of the donor liver shows a waist at the first-order left portal vein (PV) (arrow). (B, C) The ventral wall of the graft PV is longitudinally incised and a vein patch is attached. (D) The diameter of the graft PV is markedly enlarged. (E) The interposed patch (arrow) is visible at the PV anastomosis. (F) Computed tomography taken at 2 weeks after transplantation shows that the reconstructed PV appears (arrow) smoothly streamlined without stenosis.

of vascular complications in LDLT, we have established the concept of right liver graft standardization, in which every component of vascular reconstruction is repeatedly verified to observe whether the principles of hemodynamics are followed and whether it is fully compliant with graft regeneration [6,7].

Unlike adult LDLT, the condition of recipient PV is quite different in pediatric patients. The majority of adult patients have liver cirrhosis-associated portal hypertension. On the contrary, infant patients with biliary atresia usually have PV hypoplasia, thus supplying sufficient splanchnic blood flow is important for successful LT. Because the amount of splanchnic blood flow is often limited in pediatric patients, hemodynamics-compliant design of PV reconstruction is essential. If the diameter of recipient PV is inadequately small, the only solution is to make it large through progressive funneling as in the tadpole anastomosis [12].

Our techniques for $\mathrm{PV}$ reconstruction have two features. The first feature is the frequent use of vein homograft.
Since synthetic vascular grafts cannot be used for pediatric patients due to ongoing physical growth, vascular homografts should be used. The second is the funneling of the recipient $P V$ to match with the graft $P V$ recovered from the adult donors. These two features are combined in the form of funneled vein conduit using a vein homograft [12].

The availability of adequate vein homograft often influences the timing of LDLT, especially for infant patients with biliary atresia. Since synthetic vascular grafts cannot be used for pediatric patients due to their ongoing physical growth, vascular homografts should be used. We are reluctant to use cryopreserved vein grafts for PV interposition because they can degenerate over time [23]. If an adequate vein homograft for pediatric LDLT is not available from a tissue bank, we have often delayed the LT operation until a suitable vein homograft is obtained. Availability of vein homograft is beneficial to expand the indication of pediatric LDLT.

We have maintained an institutional tissue bank to sup- 


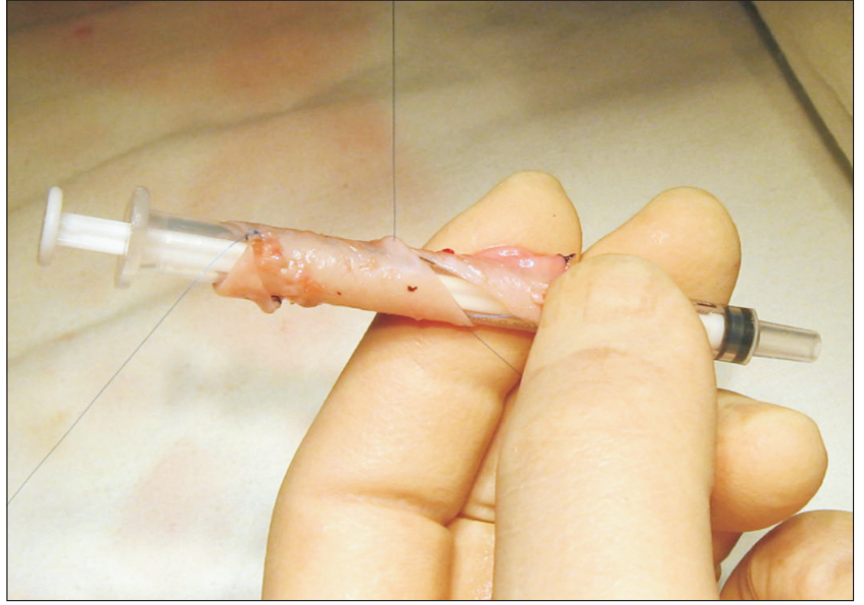

Fig. 6. Spiral winding suture to make a sizable conduit using a greater saphenous vein homograft patch.

ply various vascular homografts. All human tissues stored at the tissue bank are donated after obtaining informed consent from donors' family members. All procedures for vascular tissue procurement and processing are in compliance with Korean legislation and conform to the ethical and safety concerns for therapeutic use [24]. Currently, cryopreserved homografts of the femoral vein and artery and greater saphenous vein are commercially available through the Korea Public Tissue Bank.

If a cold-stored fresh sizable vein homograft is not available, it is possible to create a sizable conduit using cryopreserved femoral and greater saphenous veins. These veins are thick-walled than cryopreserved iliac veins, thus we think that the former is more tolerable to degeneration than the latter. However, the diameters of these veins are too small to use them directly for PV interposition, even for infant patients. Spiral winding is an effective method to make a sizable vein conduit (Fig. 6). We have occasionally used such conduits for reconstructing the middle hepatic veins for modified right liver graft implantation.

In conclusion, secure PV reconstruction is important for successful pediatric $L T$, thus every effort should be done to ensure obtainment of sufficient portal blood inflow. From the viewpoint of hemodynamics principles, a funnel-shaped $\mathrm{PV}$ conduit is the most desirable configuration than can ensure effective flow from the splanchnic system in infant patients with PV hypoplasia.

\section{FUNDING}

This study did not receive any funding.

\section{CONFLICT OF INTEREST}

All authors have no conflicts of interest to declare.

\section{ORCID}

Shin Hwang https://orcid.org/0000-0002-9045-2531 Jung-Man Namgoong

https://orcid.org/0000-0002-9237-7440

\section{AUTHORS' CONTRIBUTIONS}

Conceptualization: SH. Data curation: SH, JMN. Methodology: SH, JMN. Visualization: SH. Writing - original draft: SH, JMN. Writing - review \& editing: SH.

\section{REFERENCES}

1. Galloux A, Pace E, Franchi-Abella S, Branchereau S, Gonzales E, Pariente D. Diagnosis, treatment and outcome of hepatic venous outflow obstruction in paediatric liver transplantation: 24-year experience at a single centre. Pediatr Radiol 2018;48: 667-679.

2. Katano T, Sanada Y, Hirata Y, Yamada N, Okada N, Onishi Y, et al. Endovascular stent placement for venous complications following pediatric liver transplantation: outcomes and indications. Pediatr Surg Int 2019;35:1185-1195.

3. Zhang ZY, Jin L, Chen G, Su TH, Zhu ZJ, Sun LY, et al. Balloon dilatation for treatment of hepatic venous outflow obstruction following pediatric liver transplantation. World J Gastroenterol 2017;23:8227-8234.

4. Lu KT, Cheng YF, Chen TY, Tsang LC, Ou HY, Yu CY, et al. Efficiency of transluminal angioplasty of hepatic venous outflow obstruction in pediatric liver transplantation. Transplant Proc 2018;50:2715-2717.

5. Yeh YT, Chen CY, Tseng HS, Wang HK, Tsai HL, Lin NC, et al. Enlarging vascular stents after pediatric liver transplantation. J Pediatr Surg 2017;52:1934-1939.

6. Hwang S, Ahn CS, Kim KH, Moon DB, Ha TY, Song GW, et al. Standardization of modified right lobe grafts to minimize vascular outflow complications for adult living donor liver transplantation. Transplant Proc 2012;44:457-459.

7. Hwang S, Ha TY, Ahn CS, Moon DB, Kim KH, Song GW, et al. Standardized surgical techniques for adult living donor liver transplantation using a modified right lobe graft: a video presentation from bench to reperfusion. Korean J Hepatobiliary Pancreat Surg 2016;20:97-101.

8. Marwan IK, Fawzy AT, Egawa H, Inomata Y, Uemoto S, Asonu- 
ma K, et al. Innovative techniques for and results of portal vein reconstruction in living-related liver transplantation. Surgery 1999;125:265-270.

9. Mitchell A, John PR, Mayer DA, Mirza DF, Buckels JA, De Ville De Goyet J. Improved technique of portal vein reconstruction in pediatric liver transplant recipients with portal vein hypoplasia. Transplantation 2002;73:1244-1247.

10. Takahashi $Y$, Nishimoto $Y$, Matsuura $T$, Hayashida $M$, Tajiri $T$, Soejima $Y$, et al. Surgical complications after living donor liver transplantation in patients with biliary atresia: a relatively high incidence of portal vein complications. Pediatr Surg Int 2009; 25:745-751.

11. Ueda M, Egawa $H$, Ogawa K, Uryuhara K, Fujimoto $Y$, Kasahara $\mathrm{M}$, et al. Portal vein complications in the long-term course after pediatric living donor liver transplantation. Transplant Proc 2005;37:1138-1140.

12. Hwang S, Kim DY, Ahn CS, Moon DB, Kim KM, Park GC, et al. Computational simulation-based vessel interposition reconstruction technique for portal vein hypoplasia in pediatric liver transplantation. Transplant Proc 2013;45:255-258.

13. Namgoong JM, Hwang S, Ahn CS, Kim KM, Oh SH, Kim DY, et al. Portal vein reconstruction using side-to-side unification technique for infant-to-infant deceased donor whole liver transplantation. Ann Hepatobiliary Pancreat Surg 2020;24: 445-453.

14. Kang SH, Hwang S, Jung DH, Ahn CS, Moon DB, Ha TY, et al. Unification venoplasty to cope with recipient portal vein anomaly during living donor liver transplantation. Transplant Proc 2013;45:3000-3004.

15. Harihara Y, Makuuchi M, Kawarasaki H, Takayama T, Kubota K, Hirata $\mathrm{M}$, et al. Portal venoplasty for recipients in living-related liver transplantation. Transplantation 1999;68:1199-1200.

16. Sanada Y, Mizuta K, Kawano Y, Egami S, Hayashida M, Wakiya
T, et al. Living donor liver transplantation for congenital absence of the portal vein. Transplant Proc 2009;41:4214-4219.

17. Shinkai M, Ohhama Y, Nishi T, Yamamoto $H$, Fujita S, Take H, et al. Congenital absence of the portal vein and role of liver transplantation in children. J Pediatr Surg 2001;36:1026-1031.

18. Namgoong JM, Hwang S, Park GC, Kwon H, Kim KM, Oh SH. Living donor liver transplantation in a pediatric patient with congenital absence of the portal vein. Ann Hepatobiliary Pancreat Surg (in press).

19. Namgoong JM, Hwang S, Kim DY, Ha TY, Song GW, Jung DH, et al. Pediatric liver transplantation using a hepatitis B surface antigen-positive donor liver graft for congenital absence of the portal vein. Korean J Transplant 2021;35:59-65.

20. Kang SH, Namgoong JM, Hwang S, Jung DH, Kim KM. Wedged-patch venoplasty of the left liver graft portal vein for size matching in pediatric living donor liver transplantation. Ann Hepatobiliary Pancreat Surg 2019;23:183-186.

21. Hwang S, Lee SG, Lee YJ, Sung KB, Park KM, Kim KH, et al. Lessons learned from 1,000 living donor liver transplantations in a single center: how to make living donations safe. Liver Transpl 2006;12:920-927.

22. Moon DB, Lee SG, Hwang S, Kim KH, Ahn CS, Ha TY, et al. Toward more than 400 liver transplantations a year at a single center. Transplant Proc 2013;45:1937-1941.

23. Sugawara Y, Makuuchi M, Tamura S, Matsui Y, Kaneko J, Hasegawa $K$, et al. Portal vein reconstruction in adult living donor liver transplantation using cryopreserved vein grafts. Liver Transpl 2006;12:1233-1236.

24. Kwon $\mathrm{H}$, Kwon $\mathrm{H}$, Hong JP, Han Y, Park H, Song GW, et al. Use of cryopreserved cadaveric arterial allograft as a vascular conduit for peripheral arterial graft infection. Ann Surg Treat Res 2015;89:51-54. 